\title{
Effects of DIDS on the Chick Retinal Pigment Epithelium. II. Mechanism of the Light Peak and Other Responses Originating at the Basal Membrane
}

\author{
Ron P. Gallemore and Roy H. Steinberg \\ Departments of Physiology and Ophthalmology, University of California, San Francisco, San Francisco, California 94143
}

4,4'-diisothiocyanostilbene-2,2'-disulfonate (DIDS) appears to block a $\mathrm{Cl}^{-}$conductance in the basal membrane of the chick retinal pigment epithelium (RPE) (Gallemore and Steinberg, 1989). The present paper describes the effect of DIDS, as well as effects of anion movement blockade with other pharmacological agents, on 3 responses that originate as depolarizations of the RPE basal membrane: the light peak of the DC electroretinogram, the response to sodium azide, and the response to a small transtissue hyperosmotic gradient. Intracellular and extracellular potentials, and measurements of subretinal $\left[\mathrm{K}^{+}\right]_{0}$ were obtained from an in vitro preparation of chick retina-RPE-choroid. Choroidal perfusion with each of 4 anion transport and $\mathrm{Cl}^{-}$channel blockers (DIDS, 4-acetamido-4'-isothiocyanostilbene, phenylanthranylic acid, and thiocyanate) suppressed the light peak. DIDS, the most potent agent, abolished the basal membrane lightpeak depolarization. Choroidal perfusion with azide depolarized the basal membrane and decreased its apparent resistance, $\boldsymbol{R}_{\mathrm{ba}}$, as in cat (Linsenmeier and Steinberg, 1987). The basal membrane depolarization, recorded extracellularly as an increase in the transtissue potential (TTP), was blocked by DIDS. Azide also increased RPE c-wave amplitude, which could be explained by the decrease in $R_{\mathrm{ba}}$, and it suppressed the light peak. As previously described (Shirao and Steinberg, 1987), a 25 mOsm transtissue hyperosmotic load (retinal side hyperosmotic) increased the TTP, increased the c-wave and decreased the transtissue resistance. DIDS suppressed each of these effects. We conclude that the light peak, the response to azide, and the response to a retinal hyperosmotic load may each originate as an increase in a basal membrane anion conductance that may be permeable to chloride.

The electrical activity of the retinal pigment epithelium (RPE) is of special interest because it informs about interactions between the photoreceptors and the RPE that have physiological significance, as well as because it can be assessed in corneal recordings of the DC electroretinogram (DC ERG) (Arden and Kelsey, 1962; Kikawada, 1968). The RPE basal membrane gen-

\footnotetext{
Received July 15, 1988; revised Oct. 12, 1988; accepted Nov. 4, 1988.

Supported by NIH Grant EY01429 (R.H.S.) and, in part, by a Fight for Sight Student Fellowship (R.P.C. ), a Retinitis Pigmentosa Foundation Student Fellowship (R.P.G.), and a University of California, Irvine Dean of Biological Sciences Research Scholarship (R.P.G.).

Correspondence should be addressed to Dr. Roy H. Steinberg, Department of Physiology, S-762, University of California, San Francisco, CA 94143-0444.

Copyright (C) 1989 Society for Neuroscience $0270-6474 / 89 / 061977-08 \$ 02.00 / 0$
}

erates 2 light-dependent changes in membrane potential, the fast oscillation and the light peak (Steinberg et al., 1985), and 2 distinctive additional events that can be experimentally produced, the "azide response" (Noell, 1953; Linsenmeier and Steinberg, 1987) and the "hyperosmolarity response" (Mukoh, 1985; Shirao and Steinberg, 1987). For each of these responses, the change in basal membrane potential is accompanicd by a change in apparent membrane resistance; however, the ionic mechanism of generation for each response is not yet known.

In the previous paper, we found that the anion transport and conductance blocker 4,4'-diisothiocyanostilbene-2,2' -disulfonate (DIDS) hyperpolarizes the basal membrane, increases its apparent resistance, and increases intracellular chloride activity (Gallemore and Steinberg, 1989). These results were all consistent with blockade of a basal membrane chloride conductance. In the present paper we have studied the effects of DIDS, as well as those of other pharmacological agents thought to block anion movement, on the light peak; also studied are the effects of DIDS on the azide response and the retinal hyperosmolarity response. Portions of this work have been presented in abstract form (Gallemore and Steinberg, 1988).

\section{Materials and Methods}

Preparation and recording. Experiments were performed on retina-RPEchoroid tissues isolated from White chicks (Gallus domesticus), 1-14 d old. Methods for tissue preparation, recording, and stimulation are described fully in the accompanying paper (Gallemore and Steinberg, 1989).

While the equivalent circuit of the RPE is described in detail in the accompanying paper (Gallemore and Steinberg, 1989), the following equations will be used in the analysis of the present results:

$$
\begin{aligned}
\Delta \mathrm{TTP} & =\Delta \mathrm{TEP}+\Delta V_{R} \\
\Delta \mathrm{TEP} & =\Delta V_{\mathrm{ba}}-\Delta V_{\mathrm{ap}} \\
\Delta V_{\mathrm{ap}} & =\Delta V_{\mathrm{ba}}^{\prime} \frac{R_{\mathrm{ap}}}{R_{\mathrm{ap}}+R_{\mathrm{ba}}+R_{s}} \\
\Delta V_{\mathrm{ba}} & =\Delta V_{\mathrm{ba}}^{\prime} \frac{R_{\mathrm{ap}}+R_{s}}{R_{\mathrm{ap}}+R_{\mathrm{ba}}+R_{s}} \\
\Delta V_{\mathrm{ap}} & =\Delta V^{\prime}{ }_{\mathrm{ap}}^{\prime} \frac{R_{\mathrm{ba}}+R_{s}}{R_{\mathrm{ap}}+R_{\mathrm{ba}}+R_{s}} \\
\Delta V_{\mathrm{ba}} & =\Delta V_{\mathrm{ap}}^{\prime} \frac{R_{\mathrm{ba}}}{R_{\mathrm{ap}}+R_{\mathrm{ba}}+R_{s}}
\end{aligned}
$$

where TTP is the transtissue potential; TEP, transepithelial potential; $V_{R}$, transretinal potential; $V_{\mathrm{ap}}\left(V_{\mathrm{ba}}\right)$, measured potential of the apical (basal) membrane of the RPE; $V_{\text {ap }}^{\prime}\left(V_{\text {ba }}^{\prime}\right)$, apical (basal) membrane battery; $R_{\text {ap }}\left(R_{\mathrm{ba}}\right)$, apical (basal) membrane resistance; $R_{\mathrm{s}}$, paracellular shunt 


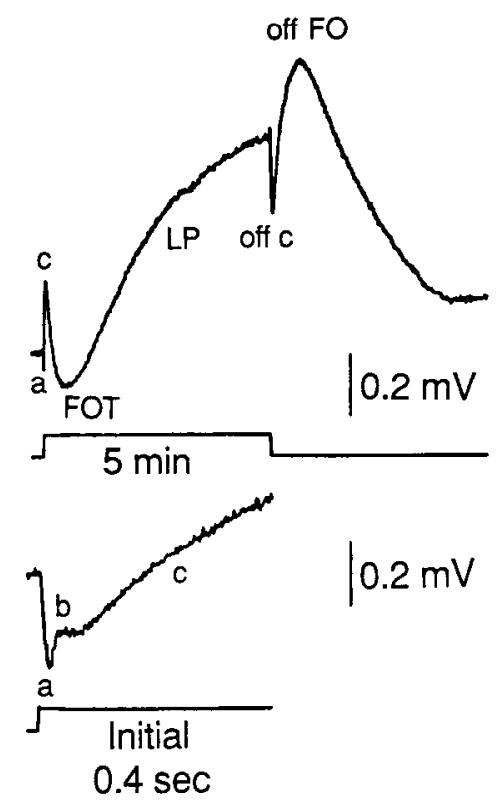

Figure 1. Chick DCERG. Responses of the chick DC ERG in temporal order are: onset of illumination-a-wave, b-wave, c-wave, fast-oscillation trough (FOT), and light peak $(L P)$; offset of illumination-off c-wave and the "off' of the fast oscillation (off $F O$ ). The stimulus (as in all figures) diffusely illuminated the retina with $6.0 \times 10^{-5} \mathrm{~W} / \mathrm{cm}^{2}$; stimulus duration was $5 \mathrm{~min}$, indicated by an upward deflection of the trace below the response. The initial components of the ERG are shown below on an expanded time scale. The apparent reduction in a-wave amplitude in the complete response is an artifact of digitization in this and all figures.

resistance. Equations 3 and 4 explain the changes in membrane potential recorded at each membrane when there is a change in a basal membrane battery (e.g., during the light peak), while Equations 5 and 6 explain the changes in membrane potential recorded at each membrane when there is a change in an apical membrane battery (e.g., during the RPE c-wave). The change in membrane potential will always be largest at the battery membrane. The change in membrane potential at the other membrane results from passive voltage drop due to the flow of "shunt current" (Miller and Steinberg, 1977; Linsenmeier and Steinberg, 1983; Griff et al., 1985). Since the TEP is defined as $V_{\text {ba }}-V_{\text {ap }}$ (Eq. 2), the RPE cwave and the light peak voltage, both originating solely as changes in TEP, will be

$$
\Delta \mathrm{TEP}=-R_{s} \frac{\Delta V_{\mathrm{ap}}^{\prime}(\mathrm{c}-\text { wave }) \text { or } \Delta V_{\mathrm{ba}}^{\prime}(\text { light peak })}{R_{\mathrm{ap}}+R_{\mathrm{ba}} \mid R_{s}}
$$

( $\Delta V_{\mathrm{ap}}^{\prime}$ and $\Delta V_{\mathrm{ba}}^{\prime}$ are negative, so $\Delta \mathrm{TEP}$ is positive.)

Solutions. The control perfusate had the following composition (solutes in $\mathrm{mM}$ ): $120.0 \mathrm{NaCl}, 25.0 \mathrm{NaHCO}_{3}, 25.0$ dextrose, $5.0 \mathrm{KCl}, 3.0$ $\mathrm{MgCl}_{2}$, and $1.8 \mathrm{CaCl}_{2}$. The test solutions were modifications of the control perfusate as follows: sodium azide $\left(\mathrm{NaN}_{3}\right)$ solutions $(100,200$, 250 , and $500 \mu \mathrm{M})$, sodium thiocyanate (NaSCN) solutions $(250,500$ and $1000 \mu \mathrm{M})$, DIDS solutions $(10,35,50,100$, and $125 \mu \mathrm{M}), 4$-acetamido-4'-isothiocyanostilbene (SITS) solutions $(35,50,100$, and 125 $\mu \mathrm{M})$, and $N$-phenylanthranylic acid (PAA) solutions $(100,225,250$, and $500 \mu \mathrm{m})$. Solutions of DIDS, SITS, and PAA were preheated to $40^{\circ} \mathrm{C}$ to facilitate solvation and were prepared in dim light due to the light sensitivity of these agents. Mannitol ( $25 \mathrm{~mm}$ ) was added to the retinal bath to produce a transtissue hyperosmotic load. The measured osmolarity of the control solution was $308 \pm 6 \mathrm{mOsm}$, while the hyperosmotic solution was $334 \pm 7$ mOsm (Advanced Wide Range Osmometer 3W2, Advanced Instruments, Needham Heights, MA). Test solutions, to which the reagent added $2.0 \mathrm{mOsm}$ or more, were made isotonic with the perfusate by removing NaCl. PAA was purchased from Aldrich (Milwaukee, WI). All other chemicals were purchased from Sigma (St. Louis, MO).

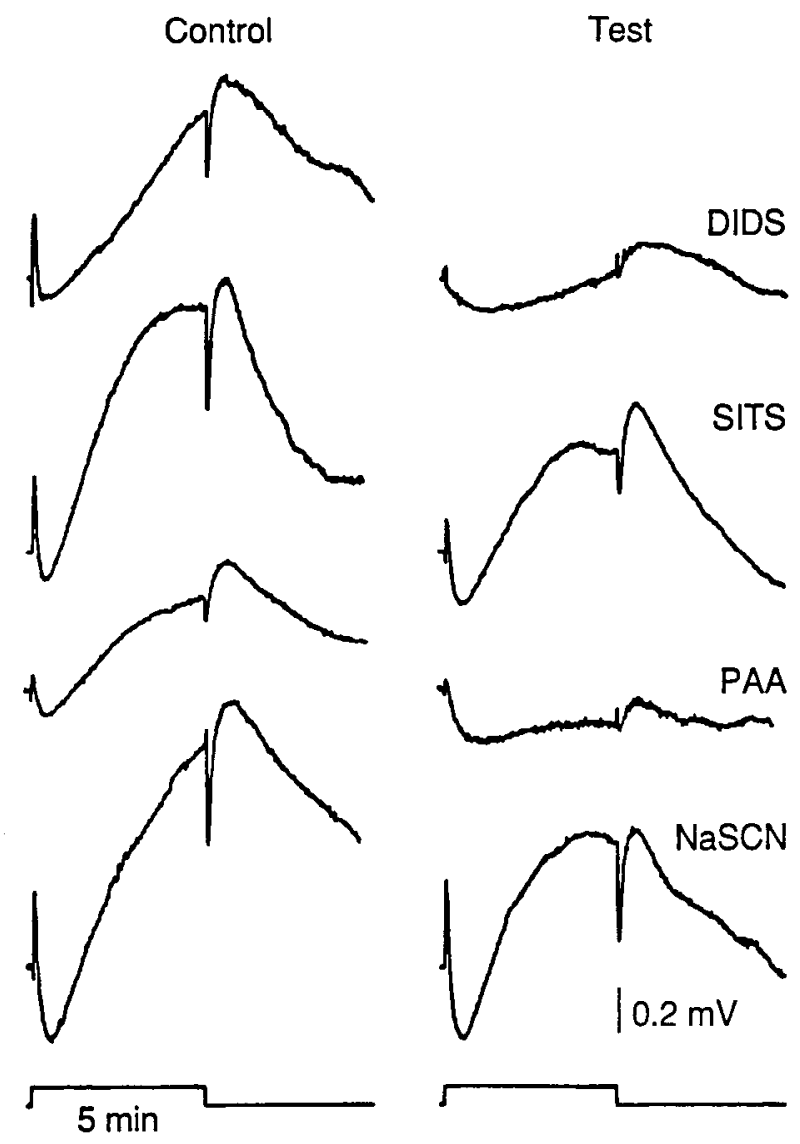

Figure 2. Anion conductance inhibitors in the choroidal bath suppress the light peak. $10 \mu \mathrm{M}$ DIDS; $200 \mu \mathrm{M}$ SITS; $225 \mu \mathrm{M} N$-phenylanthranylic acid $(P A A)$; and $500 \mu \mathrm{M}$ sodium thiocyanate (NaSCN).

\section{Results \\ DC ERG}

Figure 1 shows the $D C E R G$ of the chick neural retina-RPEchoroid preparation elicited by $5 \mathrm{~min}$ of diffuse illumination. The responsc bcgins with the ncgative a-wave, which is followed by the positive $b$-wave and then the rising phase of the $c$-wave (expanded time scale; bottom, Fig. 1). Following the c-wave (top, Fig. 1), a negative-going potential drops below the baseline, the fast-oscillation trough (FOT), which depends upon a hyperpolarization of the RPE basal membrane (Griff and Steinberg, 1984; Linsenmeier and Steinberg, 1984; van Norren and Heynen, 1986). The light peak follows in the form of a slowly rising potential that reaches maximum positivity about $5 \mathrm{~min}$ after the onset of illumination. (Light-peak amplitude is assessed as the maximum positivity during illumination, measured from the minimum of the preceding trough.) At the end of illumination the "off c-wave" (Noell, 1953; Faber, 1969; Steinberg et al., 1980) and off of the fast-oscillation (Steinberg et al., 1985) follow the light peak. As Figure 1 illustrates, the light peak is the largest and slowest component of the DC ERG.

\section{Anion movement blockade}

We examined the effect of the following anion transport and chloride channel blockers on the light peak: DIDS, SITS, PAA, and NaSCN. As illustrated in Figure 2, perfusion of the choroidal side of the tissue with each of these agents depressed the light peak (10 $\mu \mathrm{M}$ DIDS, $200 \mu \mathrm{M}$ SITS, $225 \mu \mathrm{M}$ PAA, and 500 
Control
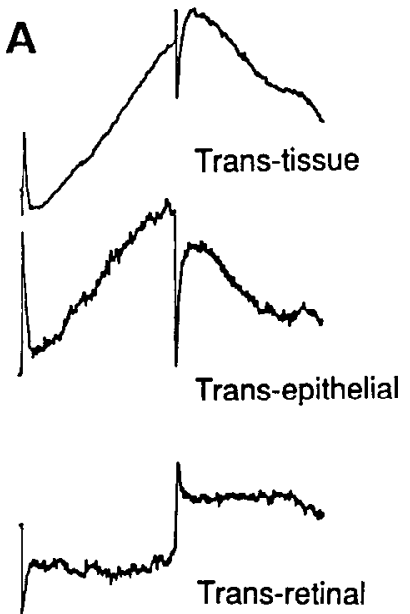

$5 \mathrm{~min}$
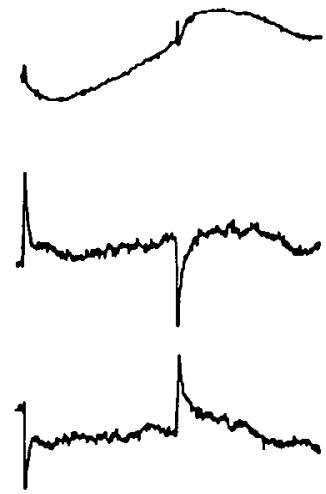

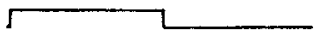

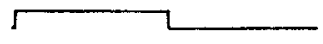

Control

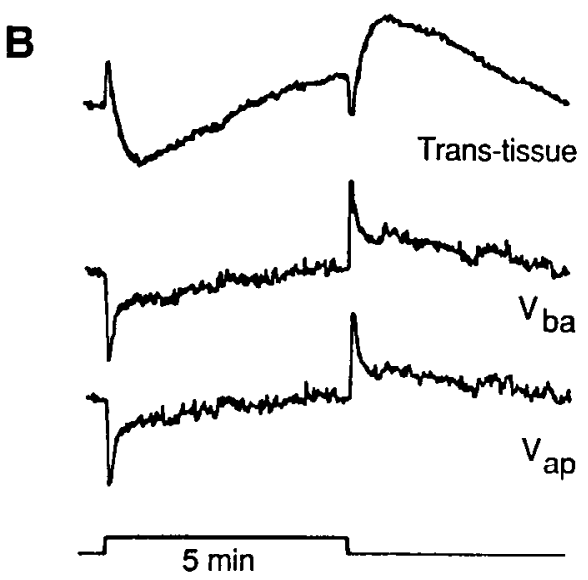

Recovery
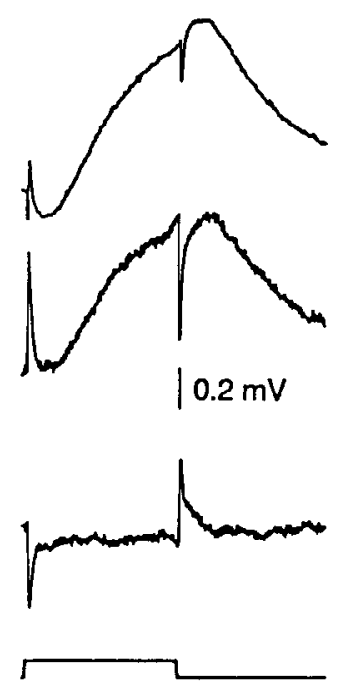

DIDS
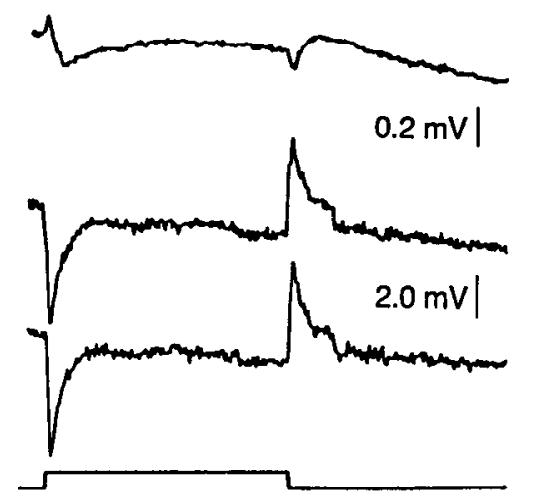

Figure 3. Effect of choroidal perfusion with DIDS on the light peak. $A$, Extracellular recording. The TTP was recorded differentially between the retinal and choroidal solutions. The transepithelial and transretinal potentials were recorded simultaneously between a microelectrode placed in the subretinal space and the choroidal and retinal reference electrodes, respectively. The control responses (left) were recorded prior to changing the choroidal perfusate to $10 \mu \mathrm{M}$ DIDS. The center responses were recorded $45 \mathrm{~min}$ after the control responses and $15 \mathrm{~min}$ following the transition to $10 \mu \mathrm{M}$ choroidal DIDS. The recovery responses were recorded about $1 \mathrm{hr}$ following the light peak in DIDS. A distinct b-wave did not appear because of its rapid time course and relatively small amplitude. The absence of the a-wave in the transretinal recording (and a-wave voltage drop in the transepithelial recording) is an artifact of digitization in this and all other ERG figures. $B$, Intracellular recording. Effect of $50 \mu \mathrm{M}$ DIDS on the intracellularly recorded light peak. The ERG was produced and recorded as in Figure 1. Simultaneously, the apical membrane potential $\left(V_{\mathrm{ap}}\right)$ was recorded differentially between the intracellular microelectrode and the retinal perfusate; the basal membrane potential $\left(V_{\mathrm{ba}}\right)$ was recorded differentially between the microelectrode and the choroidal perfusate. Control responses (left); responses in $50 \mu \mathrm{M}$ choroidal DIDS (right) $15 \mathrm{~min}$ following change from the control perfusate. The control and test responses were recorded from different cells. $\mu \mathrm{M}$ NaSCN). Previous work suggests that the selectivity of DIDS and SITS are identical, while DIDS is more potent (Knauf and Rothstein, 1971; Minocherhomjee et al., 1985). Similarly, we found that DIDS was a more potent suppressor of the light peak than SITS. For example, the reduction in light-peak amplitude for $35 \mu \mathrm{M}$ DIDS was $85 \pm 5.3 \%(n=3)$, while for $35 \mu \mathrm{M}$ SITS, it was $24 \pm 0.8 \%(n=2)$. Furthermore, to reduce the light peak by $>40 \%$ required $100 \mu \mathrm{M}$ SITS $(n=2)$, while $10 \mu \mathrm{M}$ DIDS $(n$ $=2)$ was similarly effective. All concentrations of PAA (100 $\mu \mathrm{M}$, $n=2 ; 225 \mu \mathrm{M}, n=1 ; 250 \mu \mathrm{M}, n=3$; and $500 \mu \mathrm{M}, n=1)$ suppressed the light peak $\geq 50 \%$. NaSCN was the least potent inhibitor of the light peak, reducing its amplitude an average of $39 \pm 9.4 \%$ with $500 \mu \mathrm{M}(n=2)$.

Although the stilbene derivatives SITS and the more potent DIDS can inhibit anion transport mechanisms (Knicklebein et al., 1985; Jentsch et al., 1986; Sasaki et al., 1987) and chloride conductances (Miller and White, 1979; Nelson et al., 1984; Inoue, 1985; Kimmich and Montrose, 1985), NaSCN and PAA derivatives are thought to be more selective inhibitors of chloride conductances in some systems (NaSCN: White and Miller, 1981; PAA derivatives: Distefano et al., 1985). Since the effects of DIDS on the electrical properties of the chick RPE were studied in the accompanying paper (Gallemore and Steinberg, 1989), its effects on the basal membrane responses were more thoroughly investigated in the present study.

\section{Localization of the effects of DIDS}

The light-peak voltage has been shown to originate exclusively from the RPE as a depolarization of the basal membrane (Griff and Steinberg, 1982; Linsenmeier and Steinberg, 1982; Valeton and van Norren, 1982). Recordings of the TEP and the transretinal potential in Figure $3 A$ show that the reduction of lightpeak amplitude during perfusion of the RPE basal membrane ("choroidal" perfusion) with DIDS resulted from a decline in the amplitude of the light peak in the TEP. The point here is that no new potential developed across the neural retina that could have reduced the light peak. Note that the effect of $10 \mu \mathrm{M}$ choroidal DIDS on the light peak was completely reversible. Figure $3 B$ shows that the intracellularly recorded light-peak depolarization of the basal membrane was completely abolished by perfusion of the basal membrane with $50 \mu \mathrm{M}$ DIDS (different cell). 

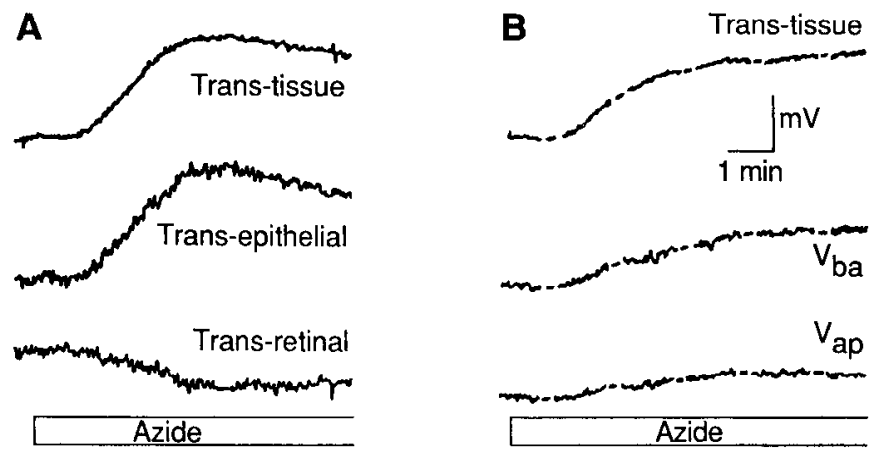

Figure 4. Effects of choroidal perfusion with sodium azide. $A$, Effect of azide $(250 \mu \mathrm{M})$ on the TTP and its transepithelial and transretinal components. $B$, Effect of azide $(500 \mu \mathrm{M})$ on RPE membrane potentials and the TTP. The TTP was recorded differentially between the retinal and choroidal perfusates. Simultaneously, the apical membrane potential $\left(V_{\text {ap }}\right)$ was recorded differentially between the intracellular microelectrode and the retinal perfusate; the basal membrane potential $\left(V_{\mathrm{ba}}\right)$ was recorded between the microelectrode and the choroidal perfusate. The perfusate was changed to the test solution containing azide as indicated at the bottom by the bars. The interruptions in the traces indicate where responses to $4 \mathrm{sec}$ flashes have becn rcmoved, without affecting the much slower time course of changes brought about by azide. Calibration: $0.5 \mathrm{mV}$ for transtissue, transepithelial, and transretinal potentials; 1.0 $\mathrm{mV}$ for $V_{\mathrm{ap}}$ and $V_{\mathrm{ba}}$.

If DIDS abolished the light peak by acting only on the RPE basal membrane, then perfusion of the retinal side of the tissue, and, therefore, the apical membrane of the RPE, might not affect the light peak, since DIDS is not thought to cross cell membranes (Cabantchick and Rothstein, 1972; Grinstein et al., 1979). We found that perfusion of both the retina and choroid or choroid alone with $35 \mu \mathrm{M}$ DIDS always suppressed the light peak, while perfusion of the retina alone never suppressed it $(n=3)$. An important question is whether DIDS reached the apical membrane of the RPE when presented retinally. We found, in fact, that $35 \mu \mathrm{M}$ DIDS in the retinal bath decreased the TEP by depolarizing the apical membrane (not shown; similar results have been reported for the frog RPE-choroid preparation; Hughes et al., 1987). Higher concentrations of retinal DIDS (50-100 $\mu \mathrm{M})$, however, began to suppress the light peak, and retinal concentrations of $100 \mu \mathrm{M}$ or greater could abolish it (not shown).

\section{Sodium azide}

\section{Effect on the TEP}

Noell $(1952,1953)$ reported that sodium azide $\left(\mathrm{NaN}_{3}\right)$ increased the standing potential in several specics, and he concluded that the effects were on the RPE. It was recently shown in cat that azide acts by depolarizing the RPE basal membrane and decreasing its resistance (Linsenmeier and Steinberg, 1987). Recently, Noell suggested (personal communication) that azide increases an anion conductance in frog oocytes, and this provided the impetus to study the azide response in chick and to determine how it is affected by DIDS. It will be useful, first, to describe the effects of sodium azide on the electrical properties of the chick tissue and on the light-evoked responses.

Figure $4 A$ shows that azide, when applied to the choroidal side of the tissue, elevated the dark-adapted TTP, and this increase was followed by a partial recovery. The potential generally remained elevated during azide perfusion, and fell to baseline after the return to control perfusate (not shown). Since the change in TEP had the same time course and was about the

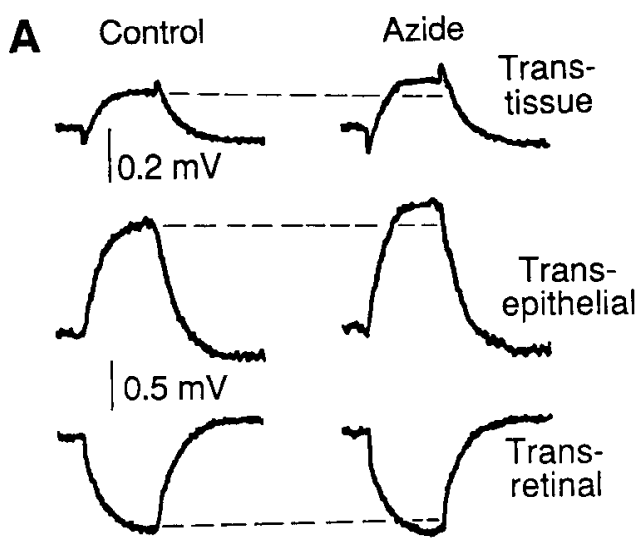

B

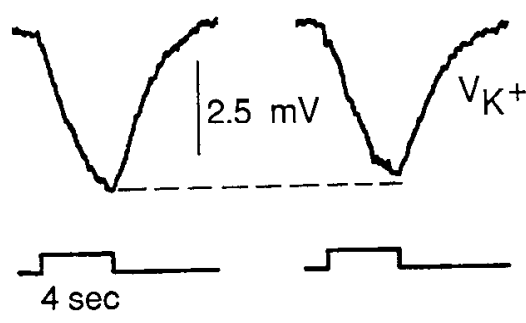

Figure 5. Effect of choroidal perfusion with sodium azide $(250 \mu \mathrm{M})$ on $(A)$ the transtissue $c$-wave and its transepithelial and transretinal components; and $(B)$ the simultaneously recorded light-evoked decrease in subretinal potassium $\left(V_{\mathrm{K}^{+}}\right)$. A $2.5 \mathrm{mV}$ change in $V_{\mathrm{K}^{+}}$corresponds to a change of approximately $0.74 \mathrm{~mm}$ in the extracellular $\mathrm{K}^{+}$level in the subretinal space, $\left[\mathrm{K}^{+}\right]_{0}$. The dark-adapted $\left[\mathrm{K}^{+}\right]_{0}$ was measured to be 5.4 $\mathrm{mm}, 0.4 \mathrm{~mm}$ greater than the control perfusate, and was not altered by azide (not shown.)

same magnitude as the change in TTP, the RPE rather than the neural retina must have been primarily responsible for it (Fig. $4 A$ ). Note, however, that as in cat (Linsenmeier and Steinberg, 1987), a small decrease in the transretinal potential also contributed to the change in TTP.

Figure $4 B$ illustrates $V_{\text {ap }}$ and $V_{\text {ba }}$ during choroidal perfusion with $500 \mu \mathrm{M}$ azide. As expected, azide depolarized both membranes but the depolarization of the basal membrane was larger and faster, indicating that the effect originated there $(n=3)$. The smaller apical membrane depolarization was likely due to shunting of the basal membrane potential through the paracellular shunt resistance (Griff et al., 1985).

\section{Effect on the c-wave and on resistances}

Perfusion of the basal membrane with azide increased the amplitude of the transtissue c-wave. Since this c-wave is the sum of a negative-going potential generated in the neural retina (slow PIII) and a positive-going potential from the RPE (RPE c-wave) (Faber, 1969; Linsenmeier and Steinberg, 1983), the increase in c-wave amplitude could have resulted from a change in either of these 2 components. Figure $5 A$ shows that both components increased during choroidal perfusion with azide, with the increase in the RPE c-wave being larger. Since an increase in slow PIII alone would decrease the c-wave, the increase in the transtissue c-wave can be attributed to an increase in its RPE component. ${ }^{1}$

\footnotetext{
I Perfusion of the choroid with azide produced a small decrease of the darkadapted transretinal potential (Fig. $4 A$ ) and an increase in the amplitude of slow PIII (transretinal in Fig. $5 A$ ), neither of which can be explained by changes in
} 


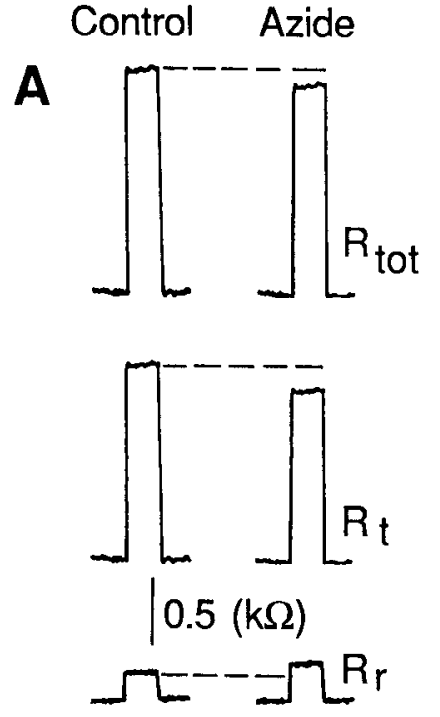

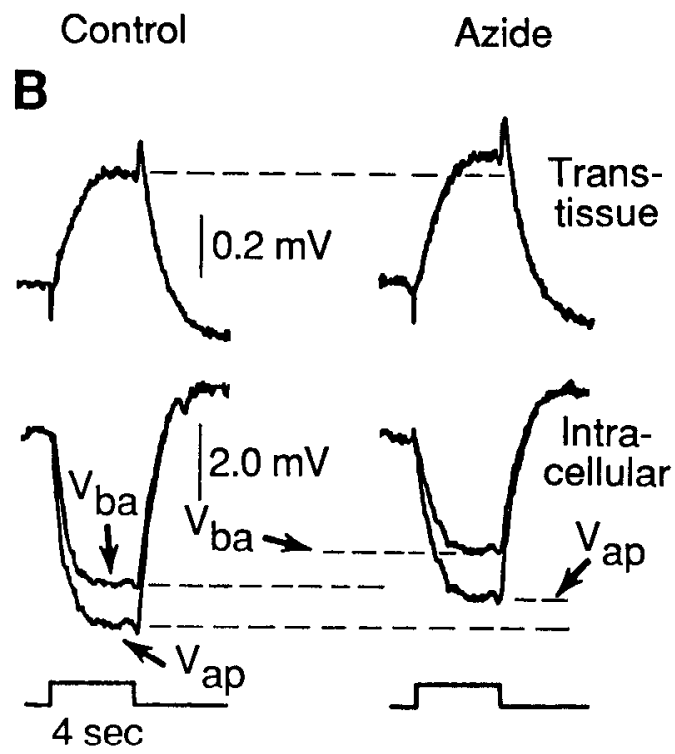

Figure 6. Assessment of azide-induced resistance changes. $A$, Effect of choroidal perfusion with azide $(250 \mu \mathrm{M})$ on the total tissue resistance $\left(K_{\mathrm{tot}}\right)$ and its components, the transretinal resistance, $R_{R}$, and the transepithelial resistance, $R_{r}$. These voltage deflections were produced by applying current pulses (1 $\mu \mathrm{A}, 1 \mathrm{sec}$ ) across the tissue with an electrode in the subretinal space. The current pulse during azide was given at the peak of the azide-induced TTP increase. Azide caused a decrease in $R_{\mathrm{tot}}$ that was due to a decrease in $R_{t}$. Note the increase in $R_{r} B$, Effect of choroidal perfusion with azide $(500 \mu \mathrm{M})$ on the intracellularly recorded $c$-wave hyperpolarizations as correlated with changes in the transtissue c-wave. The recording configuration is as in Figure $4 B$. Azide reduced both apical and basal membrane hyperpolarizations, with a greater reduction in the latter, such that the transtissue c-wave increased. This is consistent with a decrease in basal membrane resistance.
The c-wave originates from a decrease in subretinal $\left[\mathrm{K}^{+}\right]_{\text {o }}$ that hyperpolarizes the RPE, generating the RPE c-wave (Oakley and Green, 1976; Oakley, 1977; Steinberg et al., 1980), and presumably also hyperpolarizes the distal end of the Müller cell to produce slow PIII (Faber, 1969; Witkovsky et al., 1975; Karwoski and Proenza, 1977; Wen and Oakley, 1987). Thus, an increase in both components of the c-wave could result from an increase in amplitude of the light-evoked decrease in $\left[\mathrm{K}^{+}\right]_{0}$. As shown in Figure $5 B$, the light-evoked $\left[\mathrm{K}^{+}\right]_{0}$ decrease was reduced slightly $(8.3 \%$ here) by choroidal azide and, therefore, did not cause the c-wave increase $(n=2)$, corroborating a similar finding in cat (Linsenmeier and Steinberg, 1987).

Figure $6 A$ shows that azide significantly decreased the total tissue resistance $\left(R_{\mathrm{to}}\right)$. With an electrode in the subretinal space, we found that this decrease in $R_{\text {tot }}$ was due to a decrease in the RPE resistance $\left(R_{t}\right)$ and not to a decrease in neural retinal rcsistance $\left(R_{R}\right)$. However, $R_{R}$ significantly increased during azide perfusions. The decrease in $R_{t}$ could have resulted from a decrease in $R_{\mathrm{ap}}, R_{\mathrm{ba}}$, or $R_{s}$ (see Gallemore and Steinberg, 1989). One method that can be used to identify the origin of this effect involves monitoring changes in the $\mathrm{c}$-wave membrane hyperpolarizations of the RPE (Linsenmeier and Steinberg, 1983). Figure $6 B$ shows apical and basal membrane c-wave hyperpolarizations and the transtissue c-wave in response to $4 \mathrm{sec}$ flashes presented before and during choroidal perfusion with $500 \mu \mathrm{M}$ azide. Azide reduced the amplitude of both membrane hyperpolarizations, with the decrease in $V_{\mathrm{ba}}$ being larger so that an increase in the c-wave occurred. Since the light-evoked $\left[\mathrm{K}^{+}\right]_{0}$ decrease was slightly decreased, not increased, by azide (Fig. $5 B$ ), it follows from Equations 5 and 6 that only a decrease in

$\left[\mathrm{K}^{+}\right]_{\mathrm{o}}$, i.e., dark-adapled $\left[\mathrm{K}^{\dagger}\right]_{\mathrm{o}}$ was not affected (not shown) and the light-evoked $\left[\mathrm{K}^{+}\right]_{\mathrm{o}}$ decrease was reduced (Fig. $5 B$ ), which cannot produce an increase in slow PIII. At least 2 factors contributed to the increase in slow PIII (Gallemore and Steinberg, 1989), the incrcase in the transretinal resistance (Fig. $6 \mathrm{~A}$ ) and the voltage drop across the transretinal resistance $\left(R_{R}\right)$ of the RPE c-wave (Linsenmeier and Steinberg, 1987). The increase in retinal resistance could also explain the observation that azide increases the b-wave of the DC ERG by about $20 \%$ (Steinberg et al., 1985). The decrease of the dark-adapted transretinal potential may be due, in part, to the voltage drop across the transretinal resistance of the increasing TEP.
$R_{\text {ba }}$ could produce smaller c-wave hyperpolarizations accompanying an increase in the c-wave; changes in $R_{\mathrm{ap}}$ or $R_{\mathrm{s}}$ would produce different results (Eqs. 5 and 6; see also Linsenmeier and Steinberg, 1983). This supports the hypothesis, based on studies in cat, that azide decreases basal membrane resistance (Linsenmeier and Steinberg, 1987).

\section{Effect on the light peak}

Perfusion of the chick RPE basal membrane with $500 \mu \mathrm{M}$ azide abolished the light peak ( $95 \pm 0.6 \%$ reduction, $n=2), 250 \mu \mathrm{M}$ azide severely depressed the light peak (example, Fig. $7 ; 73 \pm$ $9.6 \%, n=3), 200 \mu \mathrm{M}$ depressed it less $(42 \pm 11 \%, n=6)$, and $100 \mu \mathrm{M}$ was just about ineffective. The recordings in Figure 7 show that light-peak reduction by choroidal azide $(250 \mu \mathrm{M})$ resulted from a decline in the amplitude of the transepithelial light pcak. Intracellular RPE recordings (not shown) indicated that the light-peak depolarization of the basal membrane was severely depressed by azide ( $500 \mu \mathrm{M}$ azide, $n=2)$.

While perfusing both the retina and choroid or the choroid alone with $250 \mu \mathrm{M}$ azide always suppressed the light peak, perfusing only the retina with $250 \mu \mathrm{M}$ azide did not suppress the light peak $(n=3)$. Retinal concentrations of azide of $\geq 500 \mu \mathrm{M}$, however, could suppress or abolish the light peak. In addition, retinal azide always decreased the TEP, increased RPE resistance, and reduced the c-wave, in contrast to choroidal azide.

\section{Effect of DIDS on azide-induced TTP increase}

Perfusion of the RPE basal membrane with DIDS blocked the increase in TTP normally produced by perfusing the choroid with azide. Figure 8 shows the control increase in TTP produced by azide (choroidal azide, $250 \mu \mathrm{M}$ ), its abolition in DIDS (35 $\mu \mathrm{M})$, and its recovery following DIDS perfusion. Similar results were obtained with $250 \mu \mathrm{M}$ azide in 3 experiments ( $35 \mu \mathrm{M}$ DIDS, $n=1 ; 50 \mu \mathrm{M}$ DIDS, $n=2$ ).

\section{Retinal hyperosmolarity response}

As has been previously described (Shirao and Steinberg, 1987), the dominant effects of a 25 mOsm retinal hyperosmotic load 
Figure 7. Effect of choroidal perfusion with sodium azide on the light peak. Recording configuration as in Figure $3 \mathrm{~A}$. The control responses (left) were recorded prior to changing the choroidal perfusate to $250 \mu \mathrm{M}$ azide. The center responses were recorded $45 \mathrm{~min}$ after the control response and $15 \mathrm{~min}$ following the transition to azide. The recovery responses were recorded about $1 \mathrm{hr}$ following the light peak in azide.
Azide
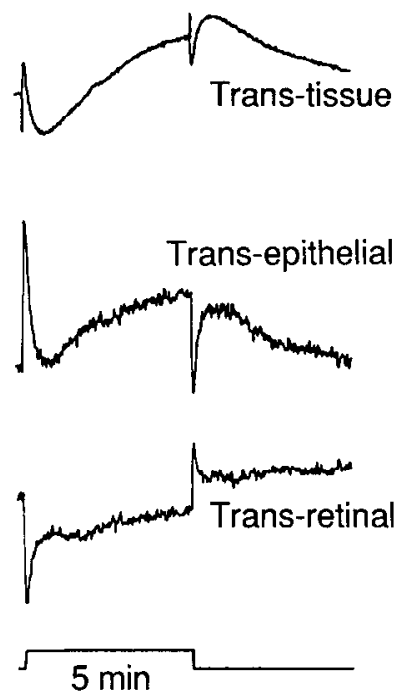
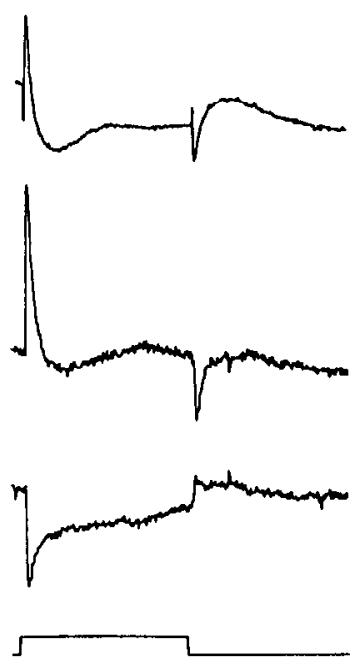

Recovery
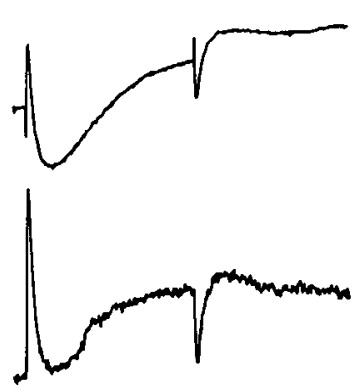

$0.2 \mathrm{mV}$

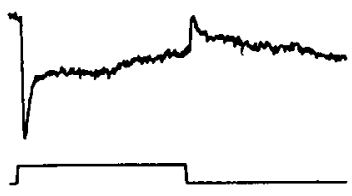

are an increase in the TTP, an increase in the c-wave, and a decrease in $R_{\text {tot }}$. As with the azide response and the light peak, these effects originate as a basal membrane depolarization accompanied by a decrease in basal membrane resistance (Shirao and Steinberg, 1987). Figure 9 illustrates the effects of introducing $25 \mathrm{~mm}$ mannitol into the retinal bath: the TTP increased by $2.2 \mathrm{mV}$ (Control, Fig. 9A), the c-wave increased by about $100 \%$ (Control, Fig. $9 B$ ), and $R_{\text {tor }}$ decreased by $11 \%$ (Control, Fig. $9 C$ ). In the same tissue, the choroidal side was perfused with DIDS $(100 \mu \mathrm{M})$. This decreased the TTP by $5.5 \mathrm{mV}$, abolished the c-wave, and increased $R_{\text {tot }}$ by $18 \%$ (not shown; Gallemore and Steinberg, 1987, 1989). A hyperosmotic load of 25 mOsm was then introduced into the retinal bath. Its effects on all 3 measures were almost completely suppressed by choroidal DIDS (DIDS, Fig. 9). Upon return to control Ringer's, recovery of all of the effects of a retinal hyperosmotic load was observed (Recovery, Fig. 9).

\section{Discussion}

Perfusing the RPE basal membrane with DIDS severely depressed 3 responses that originate there: the light peak of the DC ERG, the azide response, and the retinal hyperosmolarity response. All 3 responses are known to be generated by a depolarization of the basal membrane, which is accompanied by an apparent decrease in resistance. Data in the accompanying paper suggested that DIDS blocks a $\mathrm{Cl}^{-}$conductance at the basal membrane (Gallemore and Steinberg, 1989). Since the above responses were severely depressed by DIDS, it is possible that their generation involves some aspect of chloride movement across the RPE basal membrane.

\section{Effect of DIDS on the light peak}

The light-peak voltage originates at the basal membrane of the RPE as a depolarization accompanied by a decrease in basal membrane resistance (Griff and Steinberg, 1982; Linsenmeier and Steinberg, 1982). It is not known if the latter represents an increase in a "light-peak conductance" or is a secondary effect of the depolarization on another conductance. We have shown that micromolar concentrations of DIDS in the choroidal bath strongly depressed the light peak. Also, choroidal DIDS hyperpolarized the RPE basal membrane, increased its resistance, and increased intracellular chloride activity (Gallemore and Steinherg, 1989), results that are all consistent with chloride channel blockade. Thus, if light-peak suppression by DIDS is direct, opening of a chloride channel may contribute to the light-peak voltage. That PAA and NaSCN, thought to be more selective inhibitors of chloride channels, also suppressed the light peak, further supports the idea that the putative light-peak conductance may be permeable to chloride.

The suppression of the light peak by DIDS, however, may be indirect, i.e., by its effect on other conductances and/or transport mechanisms that result in an increase in basal membrane resistance. Such an increase in $R_{\mathrm{ba}}$, by itself, actually should produce a small increase in the light peak by reducing the shunting effect of a non-light-peak conductance in the basal membrane on the amplitude of the light-peak battery. The severe suppression of the light peak produced by DIDS suggests, then, that the light-peak mechanism is probably, itself, affected, but it does not prove that the effect is exclusively on a light-peak conductance.

An additional question concerning the effect of choroidal DIDS is whether DIDS directly affected the neural retina since the initial event in light-peak generation is light absorption by the photoreceptors. We monitored effects on photoreceptor function with 3 measures: the a-wave of the DC ERG, the light-evoked decrease in subretinal $\mathrm{K}^{+}$, and the dark-adapted subretinal $\left[\mathrm{K}^{+}\right]_{0}$ level. We found that choroidal DIDS did not alter a-wave amplitude (not shown), or the light-evoked decrease in subretinal $\mathrm{K}^{+}$, nor did it change the dark-adapted subretinal $\mathrm{K}^{+}$level (Gallemore and Steinberg, 1989). In addition, while choroidal perfusion with $35 \mu \mathrm{M}$ DIDS suppressed the light peak, perfusion of the neural retina with the same concentration did not suppress the light peak at all. These data taken together suggest that the effect of choroidal DIDS on the light peak is not through an effect on the neural retina.

\section{Effects of azide}

We confirmed the previous observation in cat that the azide effect results from a depolarization of the basal membrane (Lin- 

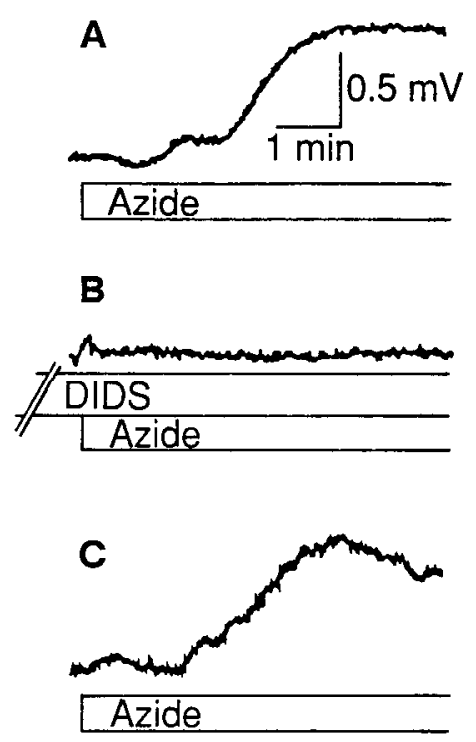

Figure 8. Effect of DIDS on the azide induced increase in TTP. A, Control increase in TTP produced by $250 \mu \mathrm{M}$ choroidal azide. $B$. Addition of azide following $15 \mathrm{~min}$ of choroidal perfusion with $35 \mu \mathrm{M}$ DIDS. $C$, Recovery of the azide induced increase in TTP.

senmeier and Steinberg, 1987) and provided new evidence that this is accompanied by a decrease in basal membrane resistance. As in cat, the increase in the transepithelial c-wave can be explained by the decrease in $R_{\mathrm{ba}}$ (see Eq. 7), and not by an increase in the light-evoked $\mathrm{K}^{+}$decrease known to generate this response (Fig. 5). We have confirmed the observation that azide suppresses the light peak (Linsenmeier and Steinberg, 1987) and showed, in addition, that this resulted from a suppression of the light-peak depolarization of the RPE basal membrane. Finally, while choroidal perfusion with $250 \mu \mathrm{M}$ azide suppressed the light peak, perfusion of the neural retina with the same concentration of azide did not. Taken together these results are consistent with choroidal azide acting directly on the RPE to reduce the light peak.

We found that retinal azide had effects opposite those of choroidal azide, decreasing the TTP, decreasing the c-wave, and increasing RPE resistance. Intravenous infusion of azide in cat (Linsenmeier and Steinberg, 1987) produces effects similar to those of choroidal perfusion in chick, i.e., on the basal membrane, as might be predicted a priori given the much higher choriocapillaris blood flow as compared with the retinal circulation.

Recent evidence indicates that azide may increase an anionic conductance in frog oocytes, which is dominated by chloride (W. Noell, personal communication). The apparent decrease in basal membrane resistance produced by azide in chick and in cat (Linsenmeier and Steinberg, 1987) suggests that azide increases basal membrane conductance. Given the observations of Noell and the suppression of the azide response by DIDS (Fig. 8), it seems plausible that azide depolarizes the basal membrane and decreases its resistance by increasing some anion conductance, perhaps $\mathrm{Cl}^{-}$, at the basal membrane.

\section{Effect of DIDS on the retinal hyperosmolarity response}

A retinal hyperosmotic load increases the TTP, increases the $\mathrm{c}$-wave and decreases total tissue resistance $\left(R_{\mathrm{tot}}\right)$. These effects have been shown to originate from a depolarization of the RPE

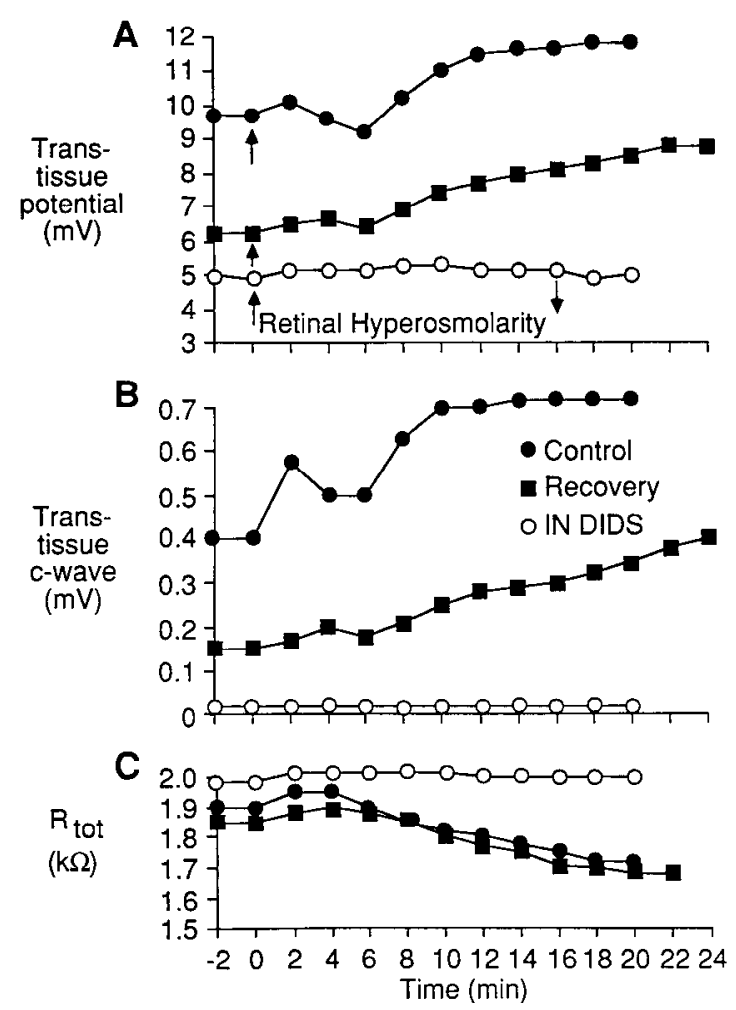

Figure 9. Effects of DIDS on the "retinal hyperosmolarity response." Arrows in $A$ indicate the onset and offset of the retinal hyperosmotic load. Note that for the Control and Recovery responses, the hyperosmotic load is maintained throughout the record following its introduction. The dominant effects of a 25 mOsm retinal hyperosmotic load are an increase in the TTP $(A$, Control $)$, an increase in the c-wave $(B$, Control $)$, and a decrease in $R_{\text {tot }}(C$, Control $)$. In the same tissue, a 25 mOsm retinal hyperosmotic load was introduced $15 \mathrm{~min}$ after choroidal perfusion with $100 \mu \mathrm{M}$ DIDS. Choroidal DIDS almost completely abolished the effects of retinal hyperosmolarity on the TTP $(A, D I D S)$, the c-wave $(B, D I D S)$, and $R_{\text {tot }}(C, D I D S)$. Following return to normal Ringer, recovery of all of the effects of a retinal hyperosmotic load was observed ( $A-C$, Recovery).

basal membrane associated with an apparent decrease in basal membrane resistance (Shirao and Steinberg, 1987). In addition, a retinal hyperosmotic load severely suppresses the light peak (Shirao and Steinberg, 1987). We were therefore interested in how DIDS might alter the response to a retinal hyperosmotic load and found that the effects of retinal hyperosmolarity on the TTP, c-wave, and $R_{\mathrm{tol}}$ were almost completely abolished by choroidal DIDS (Fig. 9). These results, given the above discussion, are consistent with the effect of retinal hyperosmolarity involving the movement of chloride across the RPE basal membrane.

In sum, we found that DIDS, which appears to block a basal membrane $\mathrm{Cl}^{-}$conductance in chick RPE (Gallemore and Steinberg, 1989), severely suppressed those responses found to originate as depolarizations of the RPE basal membrane. These responses are the light peak, the azide response, and the retinal hyperosmolarity response. Our data are consistent with the hypothesis that all of these responses originate as an increase in an anionic conductance at the RPE basal membrane that may carry $\mathrm{Cl}^{-}$. 


\section{References}

Arden, G. B., and J. H. Kelsey (1962) Changes produced by light in the standing potential of the human eye. J. Physiol. (Lond.) $161: 189$ 204.

Cabantchik, Z. I., and A. Rothstein (1972) The nature of the membrane sites controlling anion permeability of human red blood cells as determined by studies with disulfonic stilbene derivatives. J. Membr. Biol. 10: 311-330.

Distefano, A., M. Wittner, E. Schlatter, H. J. Lang, H. Englert, and R. Greger (1985) Diphenylamine-2-carboxylate, a blocker of the $\mathrm{Cl}^{-}$ conductance pathway in $\mathrm{Cl}^{-}$-transporting epithelia. Pfluegers Arch. 405: S95-S100.

Faber, D. S. (1969) Analysis of the slow transretinal potentials in response to light. Ph.D. Thesis, State I Jniv. of New York, Buffalo, NY.

Gallemore, R. P., and R. H. Steinberg (1987) Effects of the putative anion transport inhibitor DIDS on the RPE basal membrane and the c-wave. Invest. Ophthalmol. Vis. Sci. (ARVO Abstr.) 28: 382.

Gallemore, R. P., and R. H. Steinberg (1988) Evidence for a $\mathrm{Cl}^{-}$ conductance in chick retinal pigment epithelium that may contribute to responses originating at the RPE basal membrane. Soc. Neurosci. Abstr. 14: 357.

Gallemore, R. P., and R. H. Steinberg (1989) Effects of DIDS on the chick retinal pigment epithelium: I. Membrane potentials, apparent resistances, and mechanisms. J. Neurosci. 9: 1968-1976.

Gallemore, R. P., E. R. Griff, and R. H. Steinberg (1988) Evidence in support of a photoreceptoral origin for the "light-peak substance." Invest. Ophthalmol. Vis. Sci. 29: 566-571.

Griff, E. R., and R. H. Steinberg (1982) Origin of the light peak: In vitro study of Gekko gekko. J. Physiol. (Lond.) 331: 637-652.

Griff, E. R., and R. H. Steinberg (1984) Changes in apical [K+ $]_{0}$ produce delayed basal membrane responses of the retinal pigment epithelium in the gekko. J. Gen. Physiol. 83: 193-211.

Griff, E. R., Y. Shirao, and R. H. Steinberg (1985) $\mathrm{Ba}^{2+}$ unmasks K' modulation of the $\mathrm{Na}^{+}-\mathrm{K}^{+}$pump in the frog pigment epithelium. J. Gen. Physiol. 86: 853-876.

Grinstein, S., S. L. McCulloch, and A. Kothstein (1979) Transmembrane effects of irreversible inhibitors of anion transport in red blood cells: Evidence for mobile transport sites. J. Gen. Physiol. 73: 493514.

Hughes, B., S. S. Miller, J. Adorante, and S. Bialek (1987) Electrogenic $\mathrm{Na}$-dependent $\mathrm{HCO}_{3}$ transport in the apical membrane of the frog retinal pigment epithelium. Invest. Ophthalmol. Vis. Sci. (ARVO Abstr.) 28: 382

Inoue, I. (1985) Voltage-dependent chloride conductance in the squid giant axon membrane and its blockage by some disulfonic stilbene derivatives. J. Gen. Physiol. 85: 519-538.

Jentsch, T. J., I. Janicke, D. Sorgenfrei, S. K. Keller, and M. Weiderholt (1986) The regulation of intracellular $\mathrm{pH}$ in monkey kidney epithelial cells (BS-1). The roles of $\mathrm{Na}^{+} / \mathrm{K}^{+}$antiport, $\mathrm{Na}^{+}-\mathrm{HCO}_{3}{ }^{-}$symport and $\mathrm{Cl}^{-} / \mathrm{HCO}_{3}{ }^{-}$exchange. J. Biol. Chem. 261: 12120-12127.

Karwoski, C. J., and L. M. Proenza (1977) Relationship between Müller cell responses, a local transretinal potential, and potassium flux. J. Neurophysiol. 40: 244-259.

Kikawada, N. (1968) Variations in the corneo-retinal standing potential of the vertebrate eye during light and dark adaptation. Jpn. J. Physiol. 18: 687-702.

Kimmich, G. A., and M. Montrose (1985) A SITS sensitive Cl conductance pathway in chick intestinal cclls. Fcd. Proc. 44: 1743.

Knauf, P. A., and A. Rothstein (1971) Chemical modification of membranes. I. Effects of sulfhydryl and amino reactive reagents on anion and cation permeability of human red blood cells. J. Gen. Physiol. 58: $190-210$.

Knicklebein, R. G., P. S. Aronson, and J. W. Dobbins (1985) Substrate and inhibitor specificity of anion exchangers on the brush border membrane of rabbit ileum. J. Membr. Biol. 88: 199-204.

Linsenmeier, R. A., and R. H. Steinberg (1982) Origin and sensitivity of the light peak in the intact cat eye. J. Physiol. (Lond.) 331: 653673.

Linsenmeier, R. A., and R. H. Steinberg (1983) Light-evoked interaction of apical and basal membrane of retinal pigment epithelium: c-wave and light peak. J. Neurophysiol. 50: 136-147.

Linsenmeier, R. A., and R. H. Steinberg (1984) Delayed basal hyperpolarization of the cat retinal pigment epithelium, and its relation to the fast-oscillation of the DC ERG. J. Gen. Physiol. 83: 213-232.

Linsenmeier, R. A., and R. H. Steinberg (1987) Mechanisms of azide induced increases in the $c$-wave and standing potential of the intact cat eye. Vision Res. 27: 1-8.

Miller, M. M., and C. White (1979) A voltage-gated anion channel from the electric organ of Torpedo californica. J. Biol. Chem. 254: 10161-10166.

Miller, S. S., and R. H. Steinberg (1977) Passive ionic properties of frog retinal pigment epithelium. J. Membr. Biol. 36: 337-372.

Minocherhomjee, A. M., B. D. Roufogalis, and J. H. McNeill (1985) Effect of disulfonic stilbene anion-channel blockers on the guinea-pig myocardium. Can. J. Physiol. Pharmacol. 63: 912-917.

Mukoh, S. (1985) Electrical responses of the retinal pigment epithelium to hypersmolarity. Acta Soc. Ophthalmol. Jpn. 89: 482.

Nelson, D. J., J. M. Tang, and L. G. Palmer (1984) Single-channel recordings of apical membrane chloride conductance in A6 epithelial cells. J. Membr. Biol. 80: 81-89.

Noell, W. K. (1952) Azide sensitive potential difference across the eye bulb. Am. J. Physiol. 170: 217-238.

Noell, W. K. (1953) Studies on the electrophysiology and metabolism of the retina. U.S.A.F. School of Aviation Medicine, Project No. 21 1201-0004, Randolf Field, Texas.

Oakley, B., II (1977) Potassium and the photoreceptor dependent pigment epithelial hyperpolarization. J. Gen. Physiol. 70: 405-425.

Oakley, B., II, and D. G. Green (1976) Correlation of light-induced changes in retinal extracellular potassium concentration with the $c$-wave of the electroretinogram. J. Neurophysiol. 39: 1117-1133.

Sasaki, S., S. Shiagi, N. Yoshiyama, and J. Takeuchi (1987) Mechanism of bicarbonate exit across basolateral membrane of rabbit proximal straight tubule. Am. J. Physiol. 252: F11-F18.

Shirao, Y., and R. H. Steinberg (1987) Mechanisms of effects of small hyperosmotic gradients on the chick RPE. Invest. Ophthalmol. Vis. Sci. 28: 2015-2025.

Steinberg, R. H., B. Oakley II, and G. Niemeyer (1980) Light-evoked changes in $\left[\mathrm{K}^{+}\right]_{0}$ in retina of intact cat eye. J. Neurophysiol. 44: 897921 .

Steinberg, R. H., R. A. Linsenmeier, and E. R. Griff (1985) Retinal pigment epithelial cell contributions to the electrooculogram. In Progress in Retinal Research, Vol. 4, N. Osborne and G. Chader, eds. pp. 33-66, Pergamon, New York.

Valeton, J. M., and D. van Norren (1982) Intraretinal recordings of slow electrical responses to steady illumination in monkey: Isolation of receptor responses and origin of the light peak. Vision Res. 22. 393-399.

van Norren, D., and H. Heynen (1986) Origin of the fast oscillation in the electroretinogram of the macaque. Vision Res. 26: 569-575.

Wen, R., and B. Oakley II (1987) Müller cell involvement in electroretinogram generation and $\mathrm{pH}$ regulation in the vertebrate retina. Soc. Neurosci. Abstr. 13: 1049.

White, M. M., and C. Miller (1981) Probes of the conduction process of a voltage-gated $\mathrm{Cl}^{-}$channel from Torpedo electroplax. J. Gen. Physiol. 78: 1-18.

Witkovsky, P., F. E. Dudek, and H. Ripps (1975) Slow PIII component of the carp electroretinogram. J. Gen. Physiol. 65: 119-135. 